\title{
Acid-Base Changes of the Thoracic Duct Lymph during Hypercapnia and an Estimation of Cellular Contribu- tion to ECF Buffering Capacity
}

\author{
Namiyo Hata and Yoshiyuki HondA \\ Department of Physiology, Chiba University School of Medicine, \\ Chiba, 280 Japan
}

\begin{abstract}
During 90 min of spontaneous or controlled $\mathrm{CO}_{2}$ breathing in splenectomized dogs, the acid-base parameter changes of the thoracic duct lymph were compared with those of the arterial and postcaval venous blood. (1) The lymph reached an apparent steady state in the acid-base parameters at least $10 \mathrm{~min}$ after the blood. (2) The lymph bicarbonate concentration gradually increased almost in parallel with the lymph $P_{\mathrm{CO}_{2}}$ elevation, while the raised plasma bicarbonate concentration remained nearly unchanged until the end of $\mathrm{CO}_{2}$ inhalation. (3) The in vivo buffer slope of the lymph increased strikingly within $10 \mathrm{~min}$, reaching three times the in vitro slope at 90 min after inception of $\mathrm{CO}_{2}$ breathing. After 10 min, the lymph value became higher than the venous value, suggesting early cellular contribution to ECF buffering. (4) Considering the lymph values as representative of the interstitial fluid values, cellular contribution to ECF buffering was computed; they were $7.8,15.6$, and $10.7 \%$ in the spontaneously breathing group, and $8.9,10.6$, and $12.0 \%$ in the controlled ventilation group at 30,60, and $90 \mathrm{~min}$ of $\mathrm{CO}_{2}$ breathing, respectively.
\end{abstract}

Acute hypercapnia is followed by a fall in blood $\mathrm{pH}$ and a rapid rise in the plasma bicarbonate concentration. The ratio of changes of these parameters, $\Delta\left[\mathrm{HCO}_{3}^{-}\right] \mathrm{p} / \Delta \mathrm{pH}$, is generally defined as the slope of the in vivo $\mathrm{CO}_{2}$ titration curve. This slope is a composite result of the chemical and physiological buffering processes, which are (1) chemical buffering and bicarbonate redistribution throughout the extracellular fluids (ECF) including the erythrocytes, (2) ion transport from the intracellular to the extracellular fluids or vice versa, (3) bone carbonate release, and (4) renal compensation (BROWN and MicheL, 1968; NichOLS, 1958).

It has been demonstrated that the slope of the in vivo $\mathrm{CO}_{2}$ titration curve changes with the duration of hypercapnia (WoODBURY, 1974) and that during the early stage of hypercapnia, the in vivo slope is considerably lower than the

Received for publication April 23, 1981

波多奈美代，本田良行 
in vitro slope (SHAW and Messer, 1932; Brown, 1960; COHEN et al., 1964). This decrease is due primarily to redistribution of the blood-produced bicarbonate into the interstitial fluid (ISF) which has a poor buffer capacity (SHAw and Messer, 1932; Cohen et al., 1964; Brown and Michel, 1968). Thereafter, ion exchange between the intracellular and extracellular fluids (process 2), bone and renal responses (processes 3 and 4) bring about a gradual increase in the in vivo blood buffer slope (Brown and Michel, 1968; WoODBURY, 1974).

However, nonextracellular buffering, designated simply as "cellular" buffering in this paper, may contribute to the value of the in vivo slope even from the early stage of hypercapnia. To examine this hypothesis, acid-base changes in the ISF and the blood must be determined simultaneously. Since the ISF, in dynamic equilibrium with the intracellular fluid and the blood through the capillary wall, flows into the lymphatics (GuYTon et al., 1975b; Yoffey and Courtice, 1956a), we compared the time course of acid-base changes in the thoracic duct lymph with that of the blood during hypercapnia induced in dogs and estimated the cellular contribution to the buffering capacity of the ECF. Since TAKANO and NAKANO (1974) demonstrated a higher in vivo buffering capacity in the spontaneously breathing animals than that in the mechanically ventilated ones, we conducted the experiments on dogs with both types of respiration.

\section{METHODS}

Twenty mongrel dogs of both sexes, weighing 9.8 to $21.5 \mathrm{~kg}$, were used. They were anesthetized initially by i.v. injection of $25 \mathrm{mg} / \mathrm{kg}$ of sodium pentobarbital and an additional dose of $5 \mathrm{mg} / \mathrm{kg}$ every $1-2 \mathrm{hr}$ to maintain light anesthesia. Catheters were inserted into the femoral artery and into the intrathoracic portion of the postcava via femoral vein under X-ray fluoroscopy. Endotracheal intubation was performed; the airway $P_{\mathrm{CO}_{2}}$, measured by an infrared $\mathrm{CO}_{2}$ analyzer (Godart NV, Capnograph 146), was continuously displayed on a pen recorder (Hitachi, QPD-53). The rectal temperature and ECG were monitored throughout the experiments.

The animals were splenectomized to avoid possible distortion of the circulating blood buffering capacity due to a release of highly concentrated blood from the spleen (BILlings and BROWN, 1955). The thoracic duct was cannulated without pneumothorax by careful dissection at the juncture of the external jugular and the subclavian vein (MARKOwITz et al., 1964). To prevent lymph-clotting in the cannula, heparin $(200 \mathrm{U} / \mathrm{kg})$ was given intravenously.

Eleven of 20 dogs were then paralyzed by i.v. injection of $4 \mathrm{mg} / \mathrm{kg}$ of gallamine triethiodide followed by $2 \mathrm{mg} / \mathrm{kg}$ every $0.5-1 \mathrm{hr}$; they were mechanically ventilated with a respirator so as to keep the end-tidal $P_{\mathrm{CO}_{2}}$ at about 40 Torr. The other 9 dogs were allowed to breathe spontaneously.

Experimental procedures. Control observations were conducted for at least 
$30 \mathrm{~min}$ after the onset of artificial ventilation or for $1 \mathrm{hr}$ after completion of the surgical procedures. Acute hypercapnia was induced by 90 -min inhalation of a gas mixture $\left(12 \% \mathrm{CO}_{2}-30 \% \mathrm{O}_{2}\right.$ in $\left.\mathrm{N}_{2}\right)$. In the artificially ventilated dogs, the ventilation volume was increased in hypercapnia to the level 1.5 times higher than that during normocapnia. This was done to induce a similar degree of hypercapnia in both animal groups.

Arterial and postcaval venous blood and thoracic duct lymph were simultaneously collected at the end of the air-breathing period ("Control") and repeatedly at $10,20,30,60$, and $90 \mathrm{~min}$ after the onset of the $\mathrm{CO}_{2}$-breathing period ("Hypercapnia"). The volume of each blood sample was $3.5 \mathrm{ml} ; 2 \mathrm{ml}$ were transferred to a glass syringe to measure $\mathrm{pH}, P_{\mathrm{O}_{2}}$, and the hemoglobin concentration; $1.5 \mathrm{ml}$ were transferred to a plastic syringe to determine plasma $\mathrm{CO}_{2}$ content and the protein concentration. Each lymph sample was $2 \mathrm{ml}$ in volume, except for four experiments in which it was 1 to $1.5 \mathrm{ml}$ due to a lower flow rate. All samples were stored in ice water until determination of the acid-base parameters.

Analysis of acid-base parameters. Within $2 \mathrm{hr}$ of sampling, $\mathrm{pH}$ and $P_{\mathrm{O}_{2}}$ of the lymph and the blood were measured at $37^{\circ} \mathrm{C}$, using a blood gas analyzer (Radiometer, BGA2D/1-MK2). The results were corrected to the rectal temperature values, using appropriate temperature coefficients (RoSENTHAL, 1948; SEVERINGHAUS, 1965, 1966).

The $\mathrm{CO}_{2}$ content of lymph and plasma, the latter separated anaerobically in the plastic syringe, was measured by a Van Slyke micromanometer (VAN SLYKE and PlazIN, 1961). $\quad P_{\mathrm{CO}_{2}}$ and the bicarbonate concentration in the lymph and plasma were computed from the $\mathrm{CO}_{2}$ content, $\mathrm{pH}, \mathrm{p} K^{\prime}$, and the solubility coefficient for $\mathrm{CO}_{2}$ (Severinghaus, 1965) using the Henderson-Hasselbalch equation. The calculation for the lymph was carried out by using the $\mathrm{p} K^{\prime}$ and the solubility coefficient of cerebrospinal fluid (CSF), since these values in the lymph were considered to be close to those of CSF according to the theoretical estimation of SIGGAARD-ANDERSEN (1974a).

The hemoglobin concentration was colorimetrically determined by the cyanomethemoglobin method. The plasma and lymph protein concentration was measured by a refractometer (Hitachi, PRP-B).

Calculation of buffer slopes. In vitro $\mathrm{CO}_{2}$ titration was performed on the blood and lymph collected at the end of the air-breathing period and at $90 \mathrm{~min}$ of the $\mathrm{CO}_{2}$-breathing period. Each sample was equilibrated with two gas mixtures (3.59 and $7.21 \% \mathrm{CO}_{2}$ ) in a microtonometer (Radiometer, BGA2D/1-MK2) at $37^{\circ} \mathrm{C}$. From the $\mathrm{pH}$ values and the $P_{\mathrm{CO}_{2}}$ of gases, the bicarbonate concentrations were calculated by using the $\mathrm{p} K^{\prime}$ and the $\mathrm{CO}_{2}$ solubility coefficient (SEVERINGHAUS, 1965), respectively. The in vitro $\mathrm{CO}_{2}$ titration curve was drawn by connecting the two points on a $\mathrm{pH}-\left[\mathrm{HCO}_{3}^{-}\right]$diagram, and the slope of the curve was calculated in slykes (sl) (WoOdBURY, 1974).

The in vivo $\mathrm{CO}_{2}$ titration curve was drawn by connecting the "Control" and

Vol. 31, No. 6, 1981 
"Hypercapnia" $\mathrm{pH}-\left[\mathrm{HCO}_{3}^{-}\right]$points on a $\mathrm{pH}-\left[\mathrm{HCO}_{3}^{-}\right]$graph and the slope of the curve was calculated.

Estimation of ECF bicarbonate increment and cellular contribution. The general formula used to obtain the ECF bicarbonate increment was:

$$
\begin{aligned}
\mathrm{ECF} & \Delta \mathrm{HCO}_{3}^{-} \text {content }=\Delta\left(\left[\mathrm{HCO}_{3}^{-}\right] \mathrm{p} \cdot V \mathrm{p}\right)+\Delta\left(\left[\mathrm{HCO}_{3}^{-}\right] \mathrm{e} \cdot V \mathrm{c}\right) \\
& +\Delta\left(\left[\mathrm{HCO}_{3}^{-}\right] \mathrm{ISF} \cdot V_{\mathrm{ISF}}\right)
\end{aligned}
$$

in which:

$V \mathrm{p}:$

plasma volume in liter $/ \mathrm{kg}$ body weight

$V$ c: $\quad$ cell volume in liter $/ \mathrm{kg}$ body weight

$V$ ISF: interstitial fluid volume in liter $\mathrm{H}_{2} \mathrm{O} / \mathrm{kg}$ body weight

$\left[\mathrm{HCO}_{3}^{-}\right] \mathrm{p}$ : bicarbonate concentration in venous plasma in $\mathrm{mmol} / \mathrm{liter}$

$\left[\mathrm{HCO}_{3}^{-}\right] \mathrm{ISF}$ : bicarbonate concentration in interstitial fluid in mmol/liter $\mathrm{H}_{2} \mathrm{O}$

$\left[\mathrm{HCO}_{3}^{-}\right] \mathrm{e}$ : bicarbonate concentration in erythrocytes, in mmol/liter, given by Kelman's equation (Kelman, 1967; SiggaARd-Andersen, 1974b).

$$
\left[\mathrm{HCO}_{3}^{-}\right] \mathrm{e}=\left\{0.57-0.28\left(\mathrm{pH}_{\mathrm{p}}-7.40\right)-0.082\left(\mathrm{pH}_{\mathrm{p}}-7.40\right)^{2}\right\}\left[\mathrm{HCO}_{3}^{-}\right] \mathrm{p},
$$

where $\mathrm{pH}_{\mathrm{p}}$ was $\mathrm{pH}$ of venous blood.

If there are no changes in the ECF volumes during acute hypercapnia, Eq. (1) becomes:

$\mathrm{ECF} \Delta \mathrm{HCO}_{3}^{-}$content $=\Delta\left[\mathrm{HCO}_{3}^{-}\right] \mathrm{p} \cdot V \mathrm{p}+\Delta\left[\mathrm{HCO}_{3}^{-}\right] \mathrm{e} \cdot V \mathrm{c}+\Delta\left[\mathrm{HCO}_{3}^{-}\right] \mathrm{ISF} \cdot V \mathrm{ISF}$,

where $V \mathrm{p}, V \mathrm{c}$, and $V$ ISF were assumed to be 0.0451 liter $/ \mathrm{kg}, 0.0335 \mathrm{liter} / \mathrm{kg}$, and 0.1720 liter $\mathrm{H}_{2} \mathrm{O} / \mathrm{kg}$, respectively, which were obtained from 34 trials on 17 splenectomized and nephrectomized dogs using ferrocyanide and Evans blue (HATA et al., 1977).

(a) Actual bicarbonate increments (indicated as $\Delta\left[\mathrm{HCO}_{3}^{-}\right] \mathrm{ac}$ ) were computed from venous $\mathrm{pH}$ and venous and lymph bicarbonate concentrations. First, we obtained $\left[\mathrm{HCO}_{3}^{-}\right]$e by inserting venous $\mathrm{pH}$ and bicarbonate concentration into Eq. (2), and then $\Delta\left[\mathrm{HCO}_{3}^{-}\right] \mathrm{e}$, the difference between the values of "Control" and "Hypercapnia." $\Delta\left[\mathrm{HCO}_{3}^{-}\right] \mathrm{p}$ and $\Delta\left[\mathrm{HCO}_{3}^{-}\right] \mathrm{ISF}$ were also obtained from the venous plasma and lymph bicarbonate concentrations of "Control" and "Hypercapnia." $\Delta\left[\mathrm{HCO}_{3}^{-}\right] \mathrm{ac}$ were calculated by inserting these values into Eq. (3). The lymph bicarbonate concentration, in $\mathrm{mmol} /$ liter $\mathrm{H}_{2} \mathrm{O}$, was substituted for $\left[\mathrm{HCO}_{3}^{-}\right] \mathrm{ISF}$.

(b) Theoretical bicarbonate increments (defined as $\Delta\left[\mathrm{HCO}_{3}^{-}\right]$th) were computed from the physicochemical buffering capacity of the blood and ISF. For these calculations we first obtained the values of $\Delta\left[\mathrm{HCO}_{3}^{-}\right] \mathrm{p}$ and $\Delta\left[\mathrm{HCO}_{3}^{-}\right] \mathrm{ISF}$ according to the following equations, and then inserted these values into Eqs. (2) and (3): 


$$
\Delta\left[\mathrm{HCO}_{3}^{-}\right] \mathrm{p}=-\beta \mathrm{b} \cdot \Delta \mathrm{pH} \mathrm{p} \quad \text { and } \quad \Delta\left[\mathrm{HCO}_{3}^{-}\right] \mathrm{ISF}=-\beta \mathrm{ISF} \cdot \Delta \mathrm{pHISF},
$$

where $\mathrm{pH}$ and $\mathrm{pHISF}$ were $\mathrm{pH}$ of venous blood and ISF, respectively; $\beta$ ISF was in vitro slope of ISF. The lymph $\mathrm{pH}(\mathrm{pHL})$ and the buffer capacity in vitro $(\beta \mathrm{L})$ were also substituted for pHISF and $\beta$ ISF. $\beta b$ was obtained from the in vitro slope of blood $(\beta \mathrm{bo})$ by multiplying the factor 0.899 which was reported to be the ratio of body hematocrit to venous hematocrit in splenectomized dogs (REEVE et al., 1953).

$$
\beta \mathrm{b}=0.899 \beta \mathrm{bo}+0.104[\operatorname{Pr}] \mathrm{p}(1-0.899),
$$

[Pr]p: plasma protein concentration in $\mathrm{g} /$ liter.

(c) Cellular contribution to the ECF buffering capacity was computed as follows:

$$
\% \text { of cellular contribution }=\frac{\Delta\left[\mathrm{HCO}_{3}^{-}\right] \mathrm{ac}-\Delta\left[\mathrm{HCO}_{3}^{-}\right] \mathrm{th}}{\Delta\left[\mathrm{HCO}_{3}^{-}\right] \mathrm{ac}} \times 100
$$

Statistical treatment. The Student's $t$-test was applied to paired samples in the same animal group and to unpaired samples in two animal groups with different ventilatory patterns. For the estimation of an apparent equilibration time in the acid-base parameter changes, the $F$-test was applied to the differences between the "Control" and the "Hypercapnia" values. When the $F$-test demonstrated significance, the LSD method was used in comparing the adjacent pair of means (SNEDECOR and COCHRAN, 1972).

\section{RESULTS}

\section{Changes in lymph and blood acid-base parameters}

Table 1 shows the acid-base parameter changes of the lymph and blood of 9 splenectomized dogs breathing $\mathrm{CO}_{2}$ spontaneously. After inception of $\mathrm{CO}_{2}$ inhalation, the lymph $\mathrm{pH}$ decreased rapidly, reaching an apparent steady state within $20 \mathrm{~min}$. On the other hand, the lymph bicarbonate concentration increased gradually, almost in parallel with the lymph $P_{\mathrm{CO}_{2}}$ elevation, reaching an apparent steady level at between 30 and $60 \mathrm{~min}$ (Table 1 and Fig. 1C). The plasma bicarbonate concentration of arterial and venous blood increased rapidly until 10 min; thereafter, it remained almost constant. Apparent steady $\mathrm{pH}$ and $P_{\mathrm{CO}_{2}}$ values were attained earlier in the venous blood than in the lymph. Arterial blood $\mathrm{pH}$ and $P_{\mathrm{CO}_{2}}$ values rapidly reached an apparent steady level within $10 \mathrm{~min}$ (Table 1 and Figs. 1A, B).

Control $P_{\mathrm{CO}_{2}}$ value of lymph was several Torr higher than that of the mixed venous blood, and this difference increased with $P_{\mathrm{CO}_{2}}$ elevation by $\mathrm{CO}_{2}$ inhalation. These results may suggest that the continuous $P_{\mathrm{CO}_{2}}$ gradient from the tissue cell to the intravascular fluid exists and that the lymph $P_{\mathrm{CO}_{2}}$ is closer to the tissue $P_{\mathrm{CO}_{2}}$ value. 


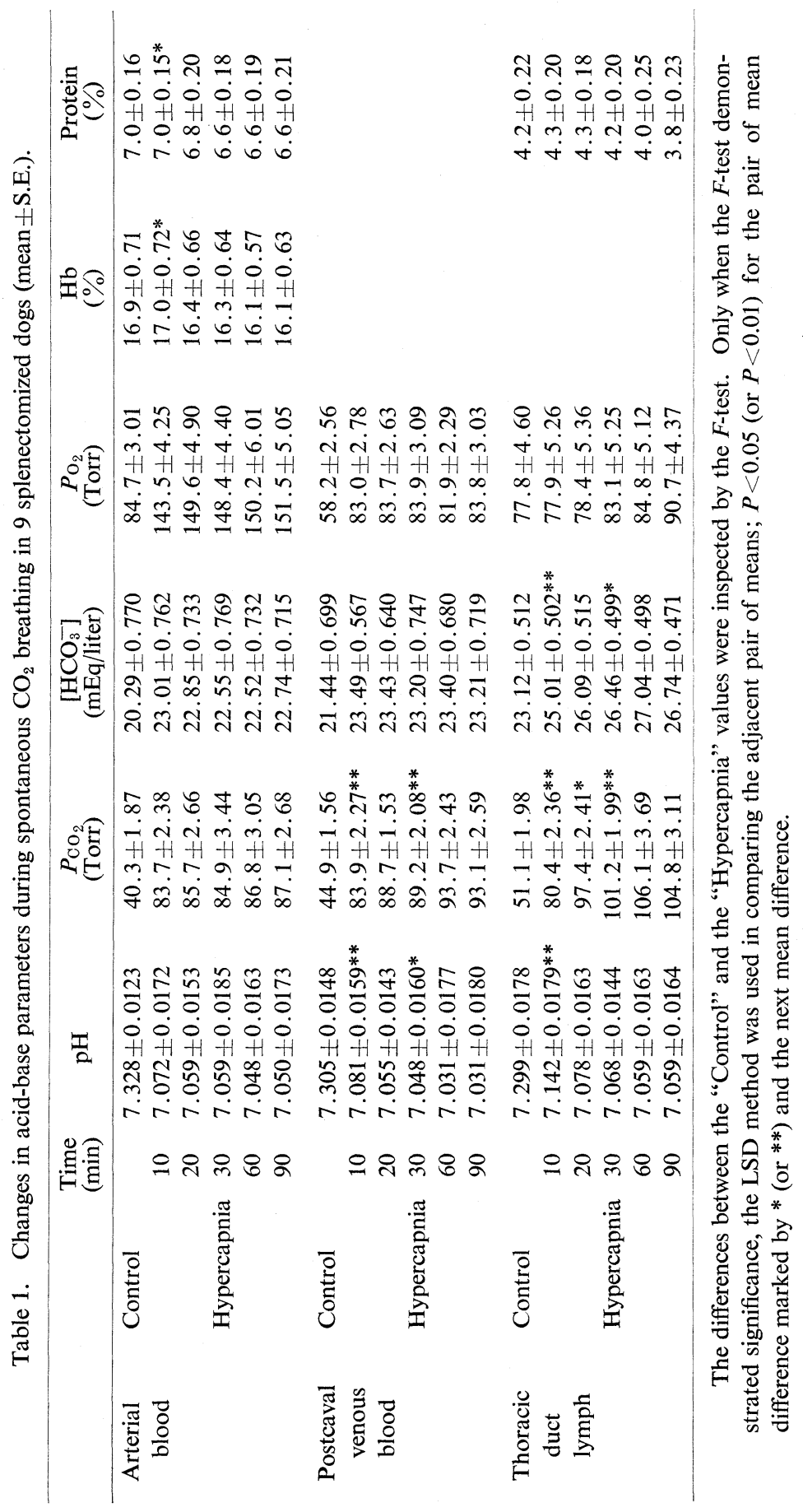




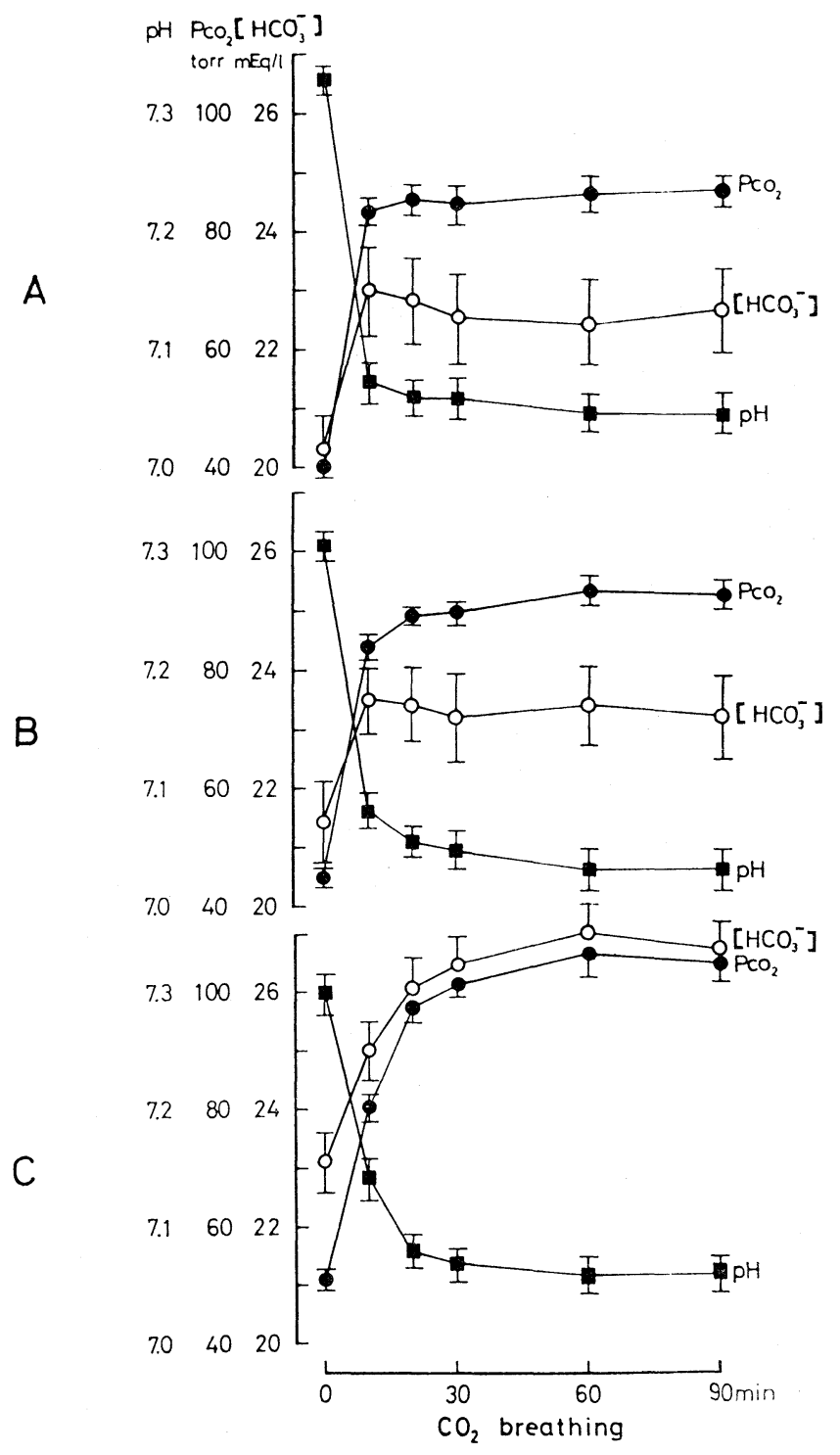

Fig. 1. Time course of acid-base parameter changes during spontaneous $\mathrm{CO}_{2}$ breathing in 9 splenectomized dogs. A, arterial blood; B, postcaval venous blood; $\mathrm{C}$, thoracic duct lymph. Vertical bars indicate the mean \pm S.E. Note that during acute hypercapnia, the lymph reached an apparent steady state in the acid-base parameters at least $10 \mathrm{~min}$ after the blood.

Similar results were obtained in the 11 splenectomized dogs subjected to controlled ventilation (Table 2). The time course of acid-base parameter changes was strikingly similar in both animal groups. During acute hypercapnia, the

Vol. 31, No. 6, 1981 


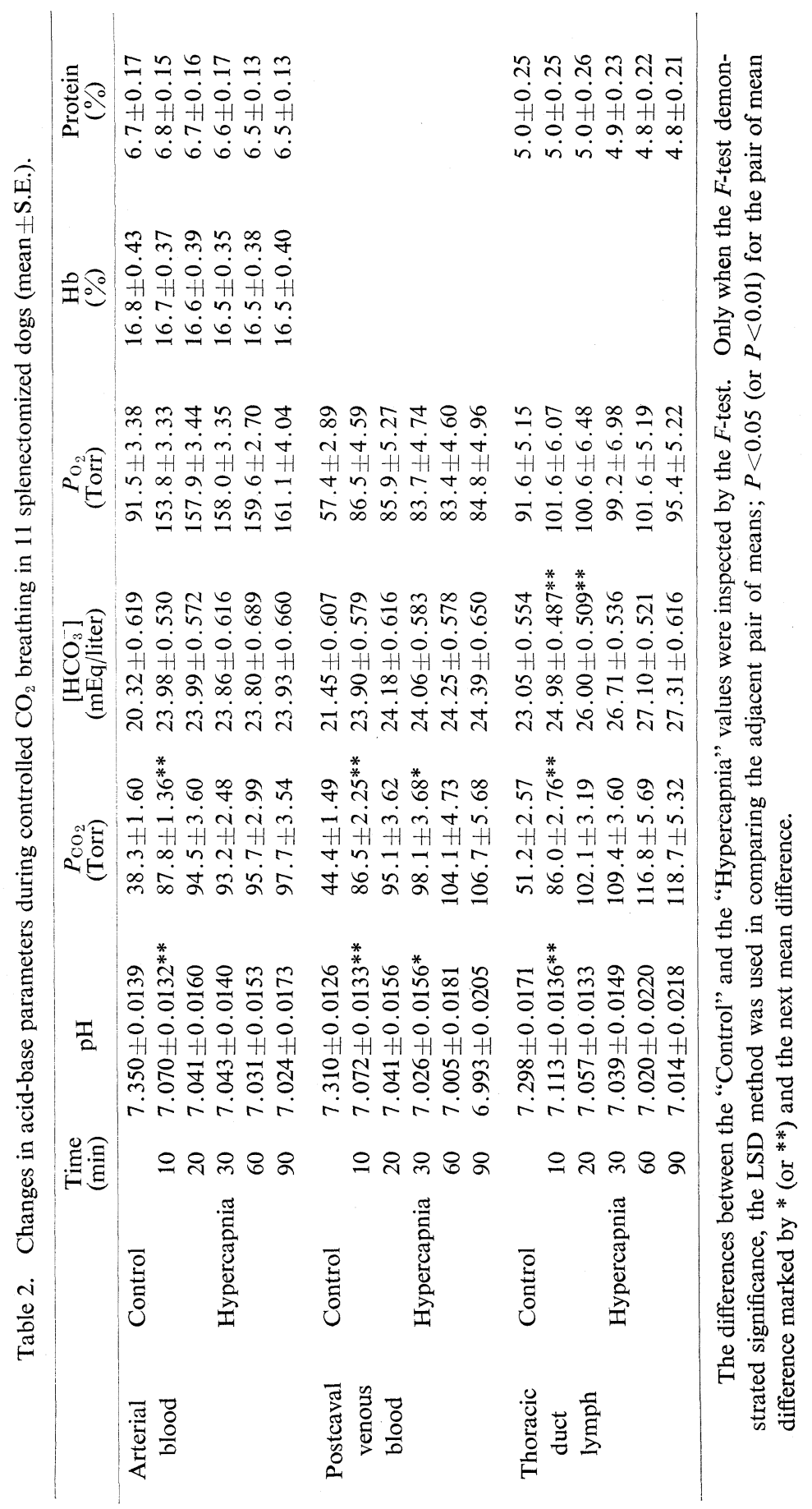


lymph reached apparently steady $\mathrm{pH}$ and $P_{\mathrm{CO}_{2}}$ values at least 10 min after the blood. The lymph bicarbonate concentration continued to increase during the first $30 \mathrm{~min}$ of hypercapnia, while there were no significant changes in the plasma bicarbonate increments after $10 \mathrm{~min}$. Increments of lymph bicarbonate concentration, corrected for the Donnan effect and water content, were significantly higher than those of venous plasma after 20 and $30 \mathrm{~min}$ of hypercapnia in the spontaneous and controlled ventilation groups, respectively $(P<0.01)$. These characteristic changes in the lymph and plasma bicarbonate concentration were reflected in the time course of in vivo buffer slope changes.

The concentration of hemoglobin and other proteins, which are the major non-bicarbonate buffers in the ECF, showed no significant changes in the controlled ventilation group. In the spontaneously breathing group, a small decrease in hemoglobin $(5 \%)$ and plasma protein concentration $(6 \%$ ) was observed after $90 \mathrm{~min}$ of hypercapnia, possibly resulting from sampling the blood and lymph (42 and $12 \mathrm{ml}$ in total, respectively) and from flushing the cannula with saline solution.

Table 3 shows the changes of the in vivo buffer slope for the lymph and blood in the spontaneous and controlled ventilation groups. The in vivo slope of the lymph increased to $12.1 \mathrm{sl}$ at $10 \mathrm{~min}$ of spontaneous $\mathrm{CO}_{2}$ breathing; this value was significantly higher than that of the venous blood $(9.1 \mathrm{sl})$ obtained at the same

Table 3. Changes in the in vivo buffer slope during spontaneous and controlled $\mathrm{CO}_{2}$ breathing in splenectomized dogs (mean \pm S.E.).

\begin{tabular}{|c|c|c|c|c|c|}
\hline & & $\begin{array}{c}\mathrm{CO}_{2} \\
\text { breathing } \\
\text { (min) }\end{array}$ & $\begin{array}{l}\text { Arterial blood } \\
\quad \text { (slyke) }\end{array}$ & $\begin{array}{c}\text { Postcaval } \\
\text { venous blood } \\
\text { (slyke) }\end{array}$ & $\begin{array}{l}\text { Thoracic } \\
\text { duct lymph } \\
\text { (slyke) }\end{array}$ \\
\hline \multirow{6}{*}{$\begin{array}{l}\text { Spontaneous } \\
\text { breathing } \\
\text { group }(n=9)\end{array}$} & in vitro slope & & $26.6 \pm 1.14$ & $26.6 \pm 1.14$ & $5.7 \pm 0.42$ \\
\hline & in vivo slope & 10 & $10.9 \pm 1.25^{*}$ & $9.1 \pm 1.03$ & $12.1 \pm 0.97^{*}$ \\
\hline & & 20 & $9.6 \pm 0.91$ & $8.0 \pm 0.74$ & $13.4 \pm 1.00^{*}$ \\
\hline & & 30 & $8.5 \pm 1.11$ & $7.0 \pm 1.09$ & $14.5 \pm 0.56$ \\
\hline & & 60 & $8.1 \pm 1.04$ & $7.2 \pm 0.67$ & $16.4 \pm 0.86$ \\
\hline & & 90 & $9.0 \pm 1.01$ & $6.5 \pm 1.01$ & $15.6 \pm 1.50$ \\
\hline \multirow{6}{*}{$\begin{array}{l}\text { Controlled } \\
\text { ventilation } \\
\text { group }(n=11)\end{array}$} & in vitro slope & & $27.7 \pm 0.82$ & $27.7 \pm 0.82$ & $5.7 \pm 0.54$ \\
\hline & in vivo slope & 10 & $13.1 \pm 0.99$ & $9.8 \pm 1.65$ & $10.2 \pm 1.12 *$ \\
\hline & & 20 & $11.9 \pm 1.06$ & $10.0 \pm 1.65$ & $12.3 \pm 1.75^{*}$ \\
\hline & & 30 & $11.6 \pm 1.30$ & $9.2 \pm 1.48$ & $14.6 \pm 1.87$ \\
\hline & & 60 & $11.0 \pm 1.37$ & $9.3 \pm 1.45$ & $15.7 \pm 2.01$ \\
\hline & & 90 & $11.4 \pm 1.41$ & $9.6 \pm 1.31$ & $16.4 \pm 2.57$ \\
\hline
\end{tabular}

The differences between the in vivo and in vitro slope values were inspected by the $F$ test. Only when the $F$-test demonstrated significance, the LSD method was used in comparing the adjacent pair of means; $P<0.05$ for the pair of mean difference marked by * and the next mean difference.

Vol. 31, No. 6, 1981 
time $(P<0.01)$. Thereafter, the lymph value increased gradually, reaching nearly three times the in vitro slope at the end of the $90-\mathrm{min}$ period. The lymph value in the spontaneously breathing group seemed to attain an equilibrium within 30 min, since further changes were not statistically significant. The in vivo slope of the venous blood exhibited an abrupt fall to about one-third the in vitro slope within $10 \mathrm{~min}$; thereafter, an apparent steady state was maintained.

In the controlled ventilation group, the in vivo slope values of the lymph were also higher than those of the venous blood after $20 \mathrm{~min}$ of $\mathrm{CO}_{2}$ inhalation $(P<$ 0.01 ). Only at $10 \mathrm{~min}$ was the increment of the lymph slope of this group (4.4 sl) lower than that of the spontaneously breathing group $(6.4 \mathrm{sl})(P<0.01)$. Under our experimental conditions, no essential differences were seen in the result between spontaneously and artificially breathing animals.

The above results strongly suggest that cellular contribution to the ECF buffering capacity may appear within $10 \mathrm{~min}$ of hypercapnia.

\section{Increase in the ECF bicarbonate content and cellular contribution}

The administered $\mathrm{CO}_{2}$ is buffered by non-bicarbonate buffers present in body fluids to produce bicarbonate. We defined the bicarbonate increment calculated by the physicochemical buffering capacity of the blood and ISF as the theoretical bicarbonate increment in the ECF. By comparing the theoretical and the actually measured bicarbonate increment, the nonextracellular or cellular contribution to the ECF bicarbonate was estimated.

Regarding the theoretical bicarbonate increments, an equilibrium with $\mathrm{CO}_{2}$ seemed to be nearly attained at about $20 \mathrm{~min}$ (broken line in Fig. 2). An apparent steady state in actual bicarbonate increments was reached about 10 min later (heavy solid line in Fig. 2). The observation that, within 20 min of $\mathrm{CO}_{2}$ inhalation, the actual value became higher than the theoretical value, suggests the addition of cellular bicarbonate to the increased ECF bicarbonate level at an early stage of hypercapnia. The magnitude of cellular contribution to the ECF buffering capacity was computed. In the spontaneously breathing group, it was 7.8, 15.6, and $10.7 \%$, and in the controlled ventilation group, it was $8.9,10.6$, and $12.0 \%$ at 30,60 , and 90 min of induced hypercapnia, respectively.

\section{DISCUSSION}

Nature of ISF bicarbonate increase and accuracy of its estimation. The actual bicarbonate increments in the ECF (blood plus ISF) progressively increased in parallel with the rise in lymph bicarbonate concentration (heavy solid line in Fig. 2), while the increments in the blood remained nearly unchanged after $10 \mathrm{~min}$ of $\mathrm{CO}_{2}$ inhalation (thin solid line in Fig. 2). The increase in lymph bicarbonate concentration is produced by ISF buffering, by bicarbonate redistribution from the blood and by cellular contribution. The processes of chemical buffering and 
A Cellular
contribution
B

$8.9 \quad 10.6$

$12.0 \%$

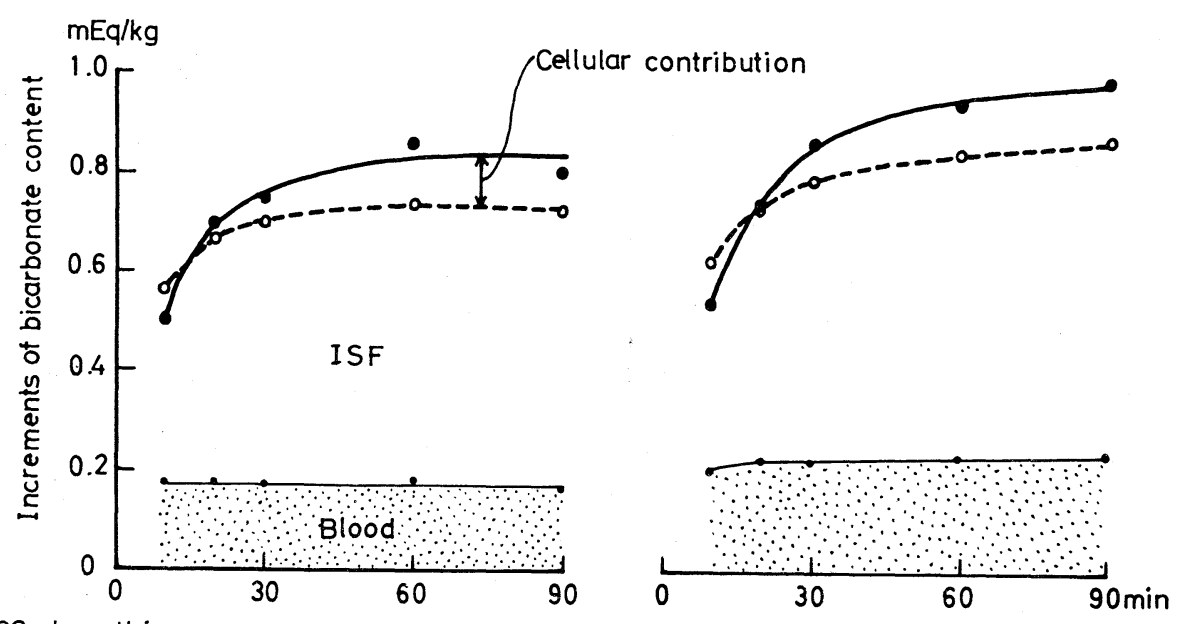

$\mathrm{CO}_{2}$ breathing

Fig. 2. Time course of ECF bicarbonate increments during spontaneous $(\mathrm{A} ; n=9)$ and controlled (B; $n=11) \mathrm{CO}_{2}$ breathing of splenectomized dogs. The heavy solid line indicates the actual bicarbonate increments in the ECF (blood plus ISF); the thin solid line, the actual increments in the blood only. The broken line indicates the theoretical bicarbonate increments, calculated from the buffering of non-bicarbonate buffers in the blood and ISF. For the calculation, see text. Note that within $20 \mathrm{~min}$ of $\mathrm{CO}_{2}$ inhalation, the actual value became higher than the theoretical one. The cellular contribution to the ECF bicarbonate increments was computed after the theoretical line reached an apparently steady level.

Table 4. Differences in estimation of cellular contribution with different ISF buffer values.

\begin{tabular}{cccc}
\hline & $\begin{array}{c}\mathrm{CO}_{2} \text { breathing } \\
(\mathrm{min})\end{array}$ & \multicolumn{2}{c}{ Cellular contribution in $\beta$ IsF taken as } \\
\cline { 3 - 4 } & 30 & $\begin{array}{c}2.1 \text { slyke } \\
(\%)\end{array}$ & $\begin{array}{c}5.7 \text { slyke } \\
(\%)\end{array}$ \\
\hline Spontaneous & 60 & 27.1 & 7.8 \\
breathing & 90 & 33.1 & 15.6 \\
group $(n=9)$ & 30 & 29.4 & 10.7 \\
Controlled & 60 & 28.2 & 8.9 \\
ventilation & 90 & 29.6 & 10.6 \\
group $(n=11)$ & 30.2 & 12.0 \\
\hline
\end{tabular}

bicarbonate redistribution in the lymph seemed to require at least $20 \mathrm{~min}$; after that period, the increase in bicarbonate concentration was greater in the lymph than in the venous plasma (Tables 1 and 2). The delay of $20 \mathrm{~min}$ or more may arise not only due to the time (10 to $20 \mathrm{~min}$ ) required for completion of chemical 
buffering and bicarbonate redistribution (Brown and MiCHEL, 1968); the transit time (10 to $15 \mathrm{~min}$ ) required for the lymph to proceed from the tissue spaces to the thoracic duct (MAYERSON, 1963; YofFeY and CourTice, 1956a) may also contribute to this delay. Our results favor the view that the sampled lymph reliably represents the bicarbonate concentration in the ISF.

Theoretical ECF bicarbonate increments are the function of $\beta \mathrm{b}, \mathrm{pH}, \beta \mathrm{L}$, and pHL. Therefore, the accuracy of the theoretical values depends on the correct approximation of the lymph and ISF values. The lymph acquired an apparently stable $\mathrm{pH}$ at least 10 min later than the venous blood (Tables 1 and 2, Fig. 1B, C); this period coincides with the above-mentioned transit time. When sufficient time is allowed for the occurrence of a new apparent steady state, changes in lymph $\mathrm{pH}$ and lymph gas tensions (BERGOFSKY et al., 1962; WiTTE et al., 1967) provide a reasonable approach in determining ISF alterations. Therefore, after the theoretical line reached an apparent steady level (broken line in Fig. 2), we computed the magnitude of cellular contribution at 30,60 , and 90 min of $\mathrm{CO}_{2}$ inhalation.

Regarding the in vitro slope of the thoracic duct lymph, the value we obtained $(5.7 \mathrm{sl})$ was higher than that of the average ISF commonly admitted (DeLL and WINTERS, 1970). The thoracic duct lymph has a higher protein concentration than the lymph from other tissues, because the liver lymph, which has the highest protein concentration, may contribute one-half of the thoracic duct flow (YOFFEY and Courtice, 1956b; MAYerson, 1963; Guyton et al., 1975c). As a high buffer value results in high theoretical bicarbonate increments, the cellular contribution to the ECF bicarbonate content may be underestimated. We computed the possible magnitude of cellular contribution, using $2.1 \mathrm{sl}$, a buffer value calculated from the average ISF having a protein concentration of $2 \%$ (GUYTON et al., 1975a) and compared the results with those that were obtained when $5.7 \mathrm{sl}$, the buffer value determined in our experiments, was used. As shown in Table 4, when the $2.1 \mathrm{sl}$ buffer value was applied, cellular contribution was around $30 \%$ in both animal groups while at $5.7 \mathrm{sl}$ it was around $10 \%$.

In the present experiments, we assumed the ECF space to be the ferrocyanide space. If, however, the chloride space, which has been preferred by DELL and WINTERS (1970) and is greater than the ferrocyanide space, is taken as the ECF space, the cellular contribution will be $20 \%$. On the other hand, when the inulin space, which has been preferred by Roos and THOMAs (1967) and is smaller than the ferrocyanide space, is taken as the ECF space, the cellular contribution will be $7 \%$. Since we focused our attention on the bicarbonate distribution in the present experiments, the readily available space to bicarbonate may well be intermediate between the chloride and the inulin space. GIEBISCH et al. (1955) thought the ${ }^{35} \mathrm{SO}_{4}^{2-}$ space to be comprised of plasma volume plus interstitial volume being in ready diffusion equilibrium with plasma, and used it in evaluating the buffering capacity of canine body fluids in respiratory acid-base disturbances; this space was similar to the ferrocyanide space (WALSER et al., 1953). Therefore, we feel 
that our preference of the ferrocyanide space in the present study is reasonable.

On deriving Eq. (3), we assumed that the ECF volumes were unaltered by $\mathrm{CO}_{2}$ inhalation. GIEBISCH et al. (1955) reported that neither the sucrose space nor ${ }^{35} \mathrm{SO}_{4}^{2-}$ space changed during hypercapnia in nephrectomized dogs, and that the calculated water shift into red cells was within the limits of error of estimating the ECF volume. We also obtained the same results in splenectomized and nephrectomized dogs using ferrocyanide (HATA et al., 1977). Regarding the changes in plasma volume during hypercapnia, the experimental data are controversal; no significant changes in splenectomized dogs (BILLINGS and Brown, 1955), or a $7 \%$ increase at $30 \mathrm{~min}$ in dogs breathing $12 \% \mathrm{CO}_{2}$ (HATA et al., 1977). If the increase in the plasma volume occurs with consequent decrease in the ISF, the cellular contribution to the ECF buffering will decrease.

The cellular contribution to the ECF buffering capacity. The present study demonstrated that cellular contribution to the ECF buffering capacity emerged in an early stage of hypercapnia; it became appreciable within $20 \mathrm{~min}$ after the onset of $\mathrm{CO}_{2}$ breathing (Fig. 2). Furthermore, after $10 \mathrm{~min}$, the in vivo slope of the lymph was significantly higher than that of the venous blood (Table 3). These observations strongly suggest that cellular contribution may appear within $10 \mathrm{~min}$ of hypercapnia. Our suggestion coincides with that of TAKANO and NAKANO (1974) who compared the predicted ratio of the in vivo to the in vitro slope for the mixed venous blood with the actual ratio obtained in $\mathrm{CO}_{2}$ breathing dogs.

In our experiments, the magnitude of cellular contribution was computed in the range of $10-30 \%$ of the ECF buffering capacity in splenectomized dogs breathing $12 \% \mathrm{CO}_{2}$ for $30-90 \mathrm{~min}$ (Table 4). GIEBISCH et al. (1955) reported it to be $51 \%$ from the estimated increments of $\mathrm{Na}$ and $\mathrm{K}$ in the ECF in nephrectomized dogs breathing $20 \% \mathrm{CO}_{2}$ for $2 \mathrm{hr}$. The difference may, in part, be attributed to their longer duration of hypercapnia.

The cellular contribution, as defined in this study, represents net bicarbonate inflow through composite processes from the tissues (nonextracellular compartments) to the ECF space. Probable processes are $\mathrm{Na}^{+}-\mathrm{H}^{+}$and $\mathrm{Cl}^{-}-\mathrm{HCO}_{3}^{-}$exchanges between intra- and extracellular fluids, which have been demonstrated in mammalian skeletal muscles (AICKIN and THOMAS, 1977) in glia cells (LOESCHCKE and Ahmad, 1980), in snail neurons (Thomas, 1976) and in squid giant axons (RUSSELl and Boron, 1976). Through these processes, more bicarbonate is likely to become available in the ECF space. On the other hand, BETTICE et al. (1976) and Strome et al. (1977) proved bicarbonate influx to the cardiac muscle, causing an increase in the buffer value in the beginning of high $\mathrm{CO}_{2}$ inhalation. Thus, the cellular contribution to the ECF bicarbonate increments is the result of the overall exchange in all tissues except erythrocytes. It also includes bone and renal responses, though their contribution to the ECF buffering capacity is probably negligible at an early stage of hypercapnia (WOODBURY, 1974; POYART et al., 1975). 
We are grateful to Miss S. Akiyama for assistance.

\section{REFERENCES}

AICKIN, C. C. and Thomas, R. C. (1977) An investigation of the ionic mechanism of intracellular pH regulation in mouse soleus muscle fibres. J. Physiol. (Lond.), 273: 295-316.

Bergofsky, E. H., Jacobson, J. H., II, and Fishman, A. P. (1962) The use of lymph for the measurement of gas tensions in interstitial fluid and tissues. J. Clin. Invest., 41: 1971-1980.

Bettice, J. A., WANG, B. C., and Brown, E. B., Jr. (1976) Intracellular buffering of heart and skeletal muscles during the onset of hypercapnia. Respir. Physiol., 28: 89-98.

Billings, H. H. and Brown, E. B., Jr. (1955) Effect of splenectomy on changes in plasma and blood volume produced by inhalation of $30 \%$ and $40 \% \mathrm{CO}_{2}$ in dogs. Am. J. Physiol., 180: 363-366.

BRown, E. B., Jr. (1960) Plasma electrolyte composition in dogs breathing high $\mathrm{CO}_{2}$ mixtures: Source of bicarbonate deficit in severe respiratory acidosis. J. Lab. Clin. Med., 55: 767-775.

Brown, E. B., Jr. and Michel, C. C. (1968) Whole body $\mathrm{CO}_{2}$ exchange. In: Abstract of the 24th International Congress of Physiological Sciences, Washington, D. C., pp. 185-186.

Cohen, J. J., BracketT, N. C., Jr., and Schwartz, W. B. (1964) The nature of the carbon dioxide titration curve in the normal dog. J. Clin. Invest., 43: 777-786.

Dell, R. B. and WiNters, R. W. (1970) A model for the in vivo $\mathrm{CO}_{2}$ equilibration curve. Am. J. Physiol., 219: 37-44.

Giebisch, G., Berger, L., and Pitts, R. F. (1955) The extra renal response to acute acid-base disturbances of respiratory origin. J. Clin. Invest., 34: 231-245.

Guyton, A. C., Taylor, A. E., and Granger, H. J. (1975a) Circulatory Physiology, Vol. II, Dynamics and Control of the Body Fluids, Chap. 2, Extracellular, intracellular, and interstitial fluids, W. B. Saunders Co., Philadelphia, pp. 10-17.

Guyton, A. C., Taylor, A. E., and Granger, H. J. (1975b) Circulatory Physiology, Vol. II, Dynamics and Control of the Body Fluids, Chap. 9, The lymphatic system-The lymphatic pump and the effect of interstitial fluid pressure and lymphatic resistance on lymph formation and flow, W. B. Saunders Co., Philadelphia, pp. 125-140.

Guyton, A. C., Taylor, A. E., and Granger, H. J. (1975c) Circulatory Physiology, Vol. II, Dynamics and Control of the Body Fluids, Chap. 15, Special fluid systems: Eye, brain, liver, intestine, muscle and bone, W. B. Saunders Co., Philadelphia, pp. 205-224.

Hata, N., Akiyama, S., Takano, N., Hirata, K., and Honda, Y. (1977) Changes in plasma and extracellular fluid volumes during acute hypercapnia, with special reference to buffering capacity of the extracellular fluids. J. Physiol. Soc. Jpn., 39: 251-252 (abstr.).

Kelman, G. R. (1967) Digital computer procedure for the conversion of $P_{\mathrm{CO}_{2}}$ into blood $\mathrm{CO}_{2}$ content. Respir. Physiol., 3: 111-115.

LOESCHCKe, H. H. and AHMAD, H. R. (1980) Anion exchange between blood, extracellular fluid of the brain and brain cells and its consequences for the respiratory control of acid-base balance. Respir. Circ., 28: 29-33.

Markowitz, J., Archibald, J., and Downie, H. G. (1964) Operative technic for cannulating the thoracic duct. In: Experimental Surgery, 5th ed., The Williams \& Wilkins Co., Baltimore, pp. 425-426.

MaYerson, H. S. (1963) The physiologic importance of lymph. In: Handbook of Physiology, Sec. 2, Circulation, Vol. II, ed. by Hamilton, W. F. and Dow, P. American Physiological Society, Washington, D. C., pp. 1035-1073.

Nichols, G., Jr. (1958) Serial changes in tissue carbon dioxide content during acute respiratory acidosis. J. Clin. Invest., 37: 1111-1122. 
Poyart, C. F., Freminet, A., and Bursaux, E. (1975) The evidence of bone $\mathrm{CO}_{2}$ in vivo. Respir. Physiol., 25: 101-107.

Reeve, E. B., Gregersen, M. I., Allen, T. H., and Sear, H. (1953) Distribution of cells and plasma in the normal and splenectomized dog and its influence on blood volume estimates with $\mathrm{P}^{32}$ and T-1824. Am. J. Physiol., 175: 195-203.

Roos, A. and Thomas, L. J., Jr. (1967) The in-vitro and in-vivo carbon dioxide dissociation curves of true plasma. A theoretical analysis. Anesthesiology, 28: 1048-1063.

Rosenthal, T. B. (1948) The effect of temperature on the pH of blood and plasma in vitro. J. Biol. Chem., 173: 25-30.

RusSELl, J. M. and BORON, W. F. (1976) Role of chloride transport in regulation of intracellular pH. Nature, 264: 73-74.

Severinghaus, J. W. (1965) Blood gas concentrations. In: Handbook of Physiology, Sec. 3, Respiration, Vol. II, ed. by FenN, W. O. and RaHN, H. American Physiological Society, Washington, D. C., pp. 1475-1487.

Severinghaus, J. W. (1966) Blood gas calculator. J. Appl. Physiol., 21: 1108-1116.

Shaw, L. A. and Messer, A. C. (1932) The transfer of bicarbonate between the blood and tissues caused by alterations of the carbon dioxide concentration in the lungs. Am. J. Physiol., 100: 122-136.

SIgGAARD-ANDERSEN, O. (1974a) The Henderson-Hasselbalch equation. In: The Acid-Base Status of the Blood, 4th ed., Munksgaard, Copenhagen, pp. 30-37.

SiggAARD-ANDERSEN, O. (1974b) The $\mathrm{CO}_{2}$ equilibration curve of oxygenated whole blood. In: The Acid-Base Status of the Blood, 4th ed., Munksgaard, Copenhagen, pp. 44-51.

Snedecor, G. W. and Cochran, W. G. (1972) Statistical Methods, 6th ed., The Iowa State University Press, Ames, pp. 271-275.

Strome, D. R., Clancy, R. L., and Gonzalez, N. C. (1977) Contribution of a net transmembrane $\mathrm{HCO}_{3}^{-}$flux to intracellular acid-base regulation. J. Appl. Physiol., 43: 931-935.

TAKANO, N. and NAKANO, E. (1974) Effect of cardiac output on the in vivo $\mathrm{CO}_{2}$ titration curve during acute breathing of $\mathrm{CO}_{2}$ in the dog. Respir. Physiol., 21: 139-155.

Thomas, R. C. (1976) Ionic mechanism of the $\mathrm{H}^{+}$pump in a snail neurone. Nature, 262: 54-55.

VAN Slyke, D. D. and Plazin, J. (1961) Micromanometric Analyses, The Williams \& Wilkins Co., Baltimore, pp. 1-55.

Walser, M., Seldin, D. W., and Grollman, A. (1953) An evaluation of radiosulfate for the determination of the volume of extracellular fluid in man and dogs. J. Clin. Invest., 32: 299311.

Witte, C. L., Clauss, R. H., and Dumont, A. E. (1967) Respiratory gas tensions of thoracic duct lymph: An index of gas exchange in splanchnic tissues. Ann. Surg., 166: 254-262.

Woodbury, J. W. (1974) Body acid-base state and its regulation. In: Physiology and Biophysics, 20th ed., Vol. II, ed. by Ruch, T. C. and Patton, H. D. W. B. Saunders Co., Philadelphia, pp. 480-524.

Yoffey, J. M. and Courtice, F. C. (1956a) Lymphatics, Lymph and Lymphoid Tissue, Chap. 2, The formation of lymph, Edward Arnold, Ltd., London, pp. 53-120.

Yoffey, J. M. and Courtice, F. C. (1956b) Lymphatics, Lymph and Lymphoid Tissue, Chap. 3, Physiological significance of regional lymphatics, Edward Arnold, Ltd., London, pp. 121219. 